\title{
Curcumin as a permeability enhancer enhanced the antihyperlipidemic activity of dietary green tea extract
}

\author{
Ashlesha P. Pandit ${ }^{1 *}$, Shreyas R. Joshi ${ }^{1}$, Preeti S. Dalal ${ }^{2}$ and Vinita C. Patole ${ }^{1}$
}

\begin{abstract}
Background: Green tea has polyphenols like flavonoids and catechins; mainly epigallocatechin-3-gallate (EGCG), epicatechin gallate (ECG), epigallocatechin (EGC) and epicatechin (EC), out of which EGCG is of higher abundance. EGCG has shown preventive role in hypercholesterolemia. However, due to low oral bioavailability, a need arises to improve its membrane permeability and transporter-mediated intestinal efflux. Therefore, an attempt was made to enhance permeability and bioavailability of EGCG using curcumin to treat hyperlipidemia. Further, it was formulated in herbal tea bags to achieve patient compliance.

Methods: EGCG extracted from green tea leaves was confirmed by High Performance Thin Layer Chromatography. Green tea extract (GTE), curcumin and their mixtures were subjected to Fourier Transform Infra-Red spectroscopy and Differential Scanning Calorimetry for compatibility studies. Powder formulation was prepared comprising GTE, curcumin, sucralose and cardamom.

Results: Ex-vivo study was performed on everted goat intestine, analyzed by HPLC and demonstrated highest permeation of GTE:curcumin (220:50) (53.15\%) than GTE (20.57\%). Antihyperlipidemic activity was performed in rats for 15 days. Blood sample analysis of rats of test groups (formulation and GTE solution) fed on high fat diet showed (mg/dl):cholesterol 80 and 90, triglycerides 73.25 and 85.5, HDL 50.75 and 46, LDL 43.9 and 46, VLDL 14.65 and 17.1 respectively with significant lipid regulating effect.

Conclusion: Curcumin enhanced permeability of EGCG. Therefore, P-glycoprotein pump inside intestine can be potential mechanism to enhance permeability of EGCG. Thus, EGCG-curcumin herbal tea bag is promising nutraceutical to treat hyperlipidemia in day-to-day life achieving patient compliance.
\end{abstract}

Keywords: Green tea extract powder, Epigallocatechin-3-gallate (EGCG), Camellia sinensis, Hyperlipidemia, Tea bags, Curcumin

\section{Background}

Herbal-based drugs are reported to have curative value for various disorders in traditional medicines [1]. Chronic diseases can be prevented by certain food possessing medicinal functions. Polyphenols are naturally occurring compounds found largely in the fruits, vegetables, cereals and beverages. Use of polyphenols has been observed to have their passable beneficial effects on human health [2]. Tea is one of the most widely consumed beverages,

\footnotetext{
* Correspondence: ashlesha.pandit@gmail.com

'Department of Pharmaceutics, JSPM's Rajarshi Shahu College of Pharmacy

and Research, Tathawade, Pune, Maharashtra 411033, India

Full list of author information is available at the end of the article
}

especially in Asia, for its long-purported health benefits [3]. Due to convincing evidence that tea is a cup of life, its consumption has increased substantially worldwide. Green tea is a variety of tea brewed from the dried leaves of the Camellia sinensis plant, belonging to Family Theaceae. Unlike other teas, green tea is not fermented. Green tea production and manufacture has spread in many countries in Asia. Green tea contains polyphenols like flavonoids containing catechins; mainly epigallocatechin-3-gallate (EGCG), epicatechin gallate (ECG), epigallocatechin (EGC), and epicatechin (EC), out of which EGCG is of higher abundance [4]. Due to oxidation of the chemical constituents of tea leaves, black tea

(c) The Author(s). 2019 Open Access This article is distributed under the terms of the Creative Commons Attribution 4.0 International License (http://creativecommons.org/licenses/by/4.0/), which permits unrestricted use, distribution, and reproduction in any medium, provided you give appropriate credit to the original author(s) and the source, provide a link to the Creative Commons license, and indicate if changes were made. The Creative Commons Public Domain Dedication waiver (http://creativecommons.org/publicdomain/zero/1.0/) applies to the data made available in this article, unless otherwise stated. 
lose its beneficial effects. However, green tea leaves have an antioxidant property [5].

Dyslipidemia is the condition mainly characterised by abnormal levels of cholesterol, triglycerides and lipoproteins, occurring more frequent in obese people. Dyslipidemia may lead to atherosclerosis induced cardiovascular complications such as high blood pressure, cardiac dysfunction, ischemic heart disease and coronary artery disease [6]. Concentration of total cholesterol in serum reflects different concentrations of lipoproteins in the serum. The major classes of lipoproteins are chylomicrons, very low density lipoproteins (VLDL), low density lipoproteins (LDL) and high density lipoproteins (HDL). In hyperlipidemia, the levels of cholesterol, triglycerides, LDL and VLDL are increased while level of HDL is decreased. Modern lifestyle and food habits are mainly responsible for this condition, and thus can be treated by diet based therapy. Green tea catechins play preventive role in obesity and related disorders mainly hypercholesterolemia and hyperglycaemia. Chronic treatment with EGCG can modulate dyslipidemia. Green tea extract has more lipidemia modulating effects than black tea extract [7].

The major components of green tea are catechins. The major catechins comprise epigallocatechin-3gallate (EGCG), epicatechin gallate (ECG), epicatechin (EC), and epigallocatechin (EgC). Most studies have attributed the various beneficial effects of green tea to EGCG, the major constituent in green tea [8]. EGCG, a type of catechin, is an ester of epigallocatechin and gallic acid. The most abundant catechin in tea is polyphenol. A great deal of attention is received by this dietary polyphenolic compounds as they are known to restore the balance between the natural antioxidants and free radicals by direct scavenging of reactive oxygen species and by enhancing the activity of natural antioxidant enzymes [9]. EGCG is water soluble and is not greatly influenced by high temperature conditions such as boiling water. It binds to many biological molecules and influences the activity of various enzymes. EGCG blocks carcinogenesis by affecting a wide array of signal transduction pathways including Jun $\mathrm{NH}_{2}$-terminal kinase/ signal transducers and activators of transcription, mitogen-activated protein kinase, phosphatidylinositol- 3-kinase/AKT [10, 11]. EGCG has shown many health promoting effects such as hypoglycaemic, hypolipidemic, anti-cancer, cardioprotective and anti-infective activity [12]. EGCG is reported to act by reducing fat absorption from gut [13] (as well as by directly inhibiting HMG Co-A reductase enzyme in hyperlipidemia [14]. Despite of these promising uses of green tea, oral bioavailability of EGCG is very low [11].The absolute bioavailability of EGCG after oral administration in rats is found to be $0.1 \%$ [15]. Low bioavailability of EGCG seems to be related to its poor membrane permeability and transporter-mediated intestinal efflux [16]. Therefore, a need arises to enhance oral bioavailability of EGCG.

Curcumin, obtained from Curcuma longa, is used as bio-enhancer for anti-microbial agents and anti-cancer drugs. It shows strong antioxidant, anti-inflammatory, anti-mutagenic and anti-carcinogenic properties. Curcumin can recover chemically-induced oxidative stress as well as increase xenobiotic detoxifying enzymes' activities in both the liver and kidneys and suppress lipid peroxidation [17]. Curcumin has low solubility and low permeability from intestine due to P-glycoprotein pump (P-gp) [18]. Curcumin acts by two mechanisms:suppression of drug metabolising enzymes in liver and inducing changes in drug transporter P-gp. Curcumin is initially absorbed from intestine, but is effluxed again inside intestine by P-gp. Curcumin and EGCG both are effluxed by P-gp; hence curcumin can play a pivotal role of inhibiting P-gp, thereby enhancing permeation of EGCG by inhibiting its efflux [19].

Piperine was found to enhance bioavailability of EGCG [20]. Encapsulation of catechin and epigallocatechin gallate (EGCG) in chitosan nanoparticles enhanced their intestinal absorption [21]. EGCG microparticles prepared by using Eudragit S100 enhancedits bioavailability by increasing contact time between nanoparticles and gut [22].

An attempt was made to use innovative method to enhance permeability of green tea constituents to improve antihyperlipidemic activity using curcumin, by inhibiting its efflux inside intestine. EGCG obtained from green tea extract was formulated in herbal tea bags with an advantage of delivering formulation in liquid form to achieve patient compliance.

\section{Materials and methods Materials}

Curcumin was procured from Loba Chemie, India. Green tea leaves and cardamom powder were procured from Ayurvedic Centre, Pune, India. All other chemicals were of analytical grade and were used as received.

\section{Methods \\ Extraction of green tea leaves}

Green tea leaves $(200 \mathrm{~g})$ reduced to suitable size were brewed in $2000 \mathrm{ml}$ of distilled water at $50^{\circ} \mathrm{C}$ for $10 \mathrm{~min}$ in a thermostat heating mantle ( $\mathrm{J}$ B Scientific, India). Temperature was increased to $80^{\circ} \mathrm{C}$ and heated for further $10 \mathrm{~min}$. Solution obtained was dried to powder using vacuum evaporator (Equitron-Evator Medica Instruments, Mumbai).Powder was triturated to reduce particle size for further studies [23]. 


\section{Characterizations of green tea extract powder Yield and flow properties}

Green tea extract powder (GTE) was weighed and evaluated for properties such as physical appearance, density, compressibility index, Hausner's ratio and angle of repose. Preliminary phytochemical screening was done for EGCG by performing catecholic tannin test as follows: $0.5 \mathrm{ml}$ of extract was dissolved in $1 \mathrm{ml}$ of water and mixed thoroughly. Two drops of ferric chloride solution was added to it. Solution was observed for green black colour for presence of catecholic tannin.

\section{Analysis of green tea extract by HPTLC for EGCG}

Green tea extract was characterized by HPTLC (CAMAG, Switzerland). The mobile phase used was toluene: acetone: formic acid (9:9:2). Sample solution of 1 to $15 \mu \mathrm{L}$ was applied as $8 \mathrm{~mm}$ band from lower edge of the plate. Plates were developed over $6 \mathrm{~cm}$ from lower edge of plate using an unsaturated trough chamber $[24,25]$.

Derivatization for polyphenols was done by heating the plate at $100^{\circ} \mathrm{C}$ for $2 \mathrm{~min}$ followed by dipping the hot plate in fast blue salt B reagent. Further, plate was dried in a fume hood for $5 \mathrm{~min}$ after derivatization and evaluated for $R_{f}$ value.

\section{Infra-red spectroscopy}

Curcumin, green tea extract and mixture were analysed by FT-IR (Alpha Bruker, Germany) to get spectra. Samples in powder form were placed on sample holder in sufficient amount and tightened with upper probe. Samples were analysed using Opus software to get IR spectra.IR spectrum of green tea extract was compared with standard spectrum to confirm EGCG.

\section{Differential scanning calorimetry}

Green tea extract, curcumin and their mixture (1:1) were identified using differential scanning calorimetry (DSC1, Mettler Toledo, Switzerland).

\section{Determination of tensile strength of tea bags}

Tensile strength of tea bags was measured using CT3 Texture Analyzer (Brookfield Engineering Corporation, USA) intension mode by using TA-DGA (Dual Grip Assembly) accessory in TA-P-KIT.

\section{Formulation of tea bags}

\section{Preliminary trials}

Preliminary study of formulation was performed by trial and error batches with varying concentrations of green tea extract (150 to $300 \mathrm{mg}$ ) and curcumin powder (25 to $100 \mathrm{mg}$ ). Ex-vivo study of these batches was performed to study effect of curcumin on permeability of green tea extract. Batches showing good permeability were selected for further formulation.

Green tea extract (180 to $220 \mathrm{mg}$ ) and curcumin powder $(25$ to $75 \mathrm{mg}$ ) were lightly triturated in mortar and pestle. Sucralose and cardamom powder were added as artificial sweetener and flavouring agent respectively, to the above mixture, again triturated and mixed in planetary mixer (Avon, India) to obtain tea powder mixture. Formulation batches of tea powder (F1 to F9) are as shown in Table 1. A single use tea powder (about $2.2 \mathrm{~g}$ ) was filled carefully in tea bags and sealed. Tea solution was prepared by dunking tea bag and moving up-down for $5 \mathrm{~min}$ in $100 \mathrm{ml}$ preheated $\left(80^{\circ} \mathrm{C}\right)$ distilled water. Solution was allowed to cool at $37^{\circ} \mathrm{C}$ and used for further studies.

\section{Evaluation of tea bags Drug content}

Drug content (EGCG) of F1 to F9 batches was determined. Tea bags were dunk in $100 \mathrm{ml}$ water (pre-heated to $80^{\circ} \mathrm{C}$ ), moving up-down for $5 \mathrm{~min}$ and cooled to $37^{\circ} \mathrm{C}$. Aliquot $(5 \mathrm{ml})$ was withdrawn after $5 \mathrm{~min}$. Suitable dilutions were made and drug content was estimated at $274 \mathrm{~nm}$ using UV spectrophotometer (1800, Shimadzu, Japan) and distilled water as a blank solution.

\section{Ex-vivo study}

In vitro continuous dissolution-absorption system design was used to study amount of drug permeated intestine using everted intestine [26]. Fresh small intestine of goat was brought from slaughter-house with supplement of tyrode solution $\mathrm{pH} 6.5(8 \mathrm{~g} \mathrm{NaCl}, 1 \mathrm{~g}$ Glucose, $1 \mathrm{~g}$ $\mathrm{NaHCO}_{3}, 0.2 \mathrm{~g} \mathrm{CaCl}_{2}, 0.2 \mathrm{~g} \mathrm{KCl}, 0.1 \mathrm{~g} \mathrm{MgCl}_{2}, 0.05 \mathrm{~g}$ $\mathrm{NaH}_{2} \mathrm{PO}_{4}$ ). Intestine was carefully manoeuvred to find ileum part. Suitable length of ileum $(5 \mathrm{~cm})$ was cut off, everted using glass rod (Fig. 1c), cleaned in supplement of fresh tyrode solution and attached to U-shaped apparatus (Fig. 1a). In-vitro drug permeation study of formulation was carried out in1000 $\mathrm{ml}$ container having

Table 1 Formulation of green tea extract in tea bags

\begin{tabular}{|c|c|c|c|c|c|c|c|c|c|}
\hline Ingredient & F1 & F2 & F3 & F4 & F5 & F6 & F7 & F8 & F9 \\
\hline Green tea extract (mg) & 220 & 220 & 220 & 200 & 200 & 200 & 180 & 180 & 180 \\
\hline Curcumin (mg) & 25 & 50 & 75 & 25 & 50 & 75 & 25 & 50 & 75 \\
\hline Sucralose (mg) & 2000 & 2000 & 2000 & 2000 & 2000 & 2000 & 2000 & 2000 & 2000 \\
\hline Cardamom (mg) & q. s. & q. s. & q. s. & q. s. & q. s. & q. s. & q. s. & q. s. & q. s. \\
\hline
\end{tabular}




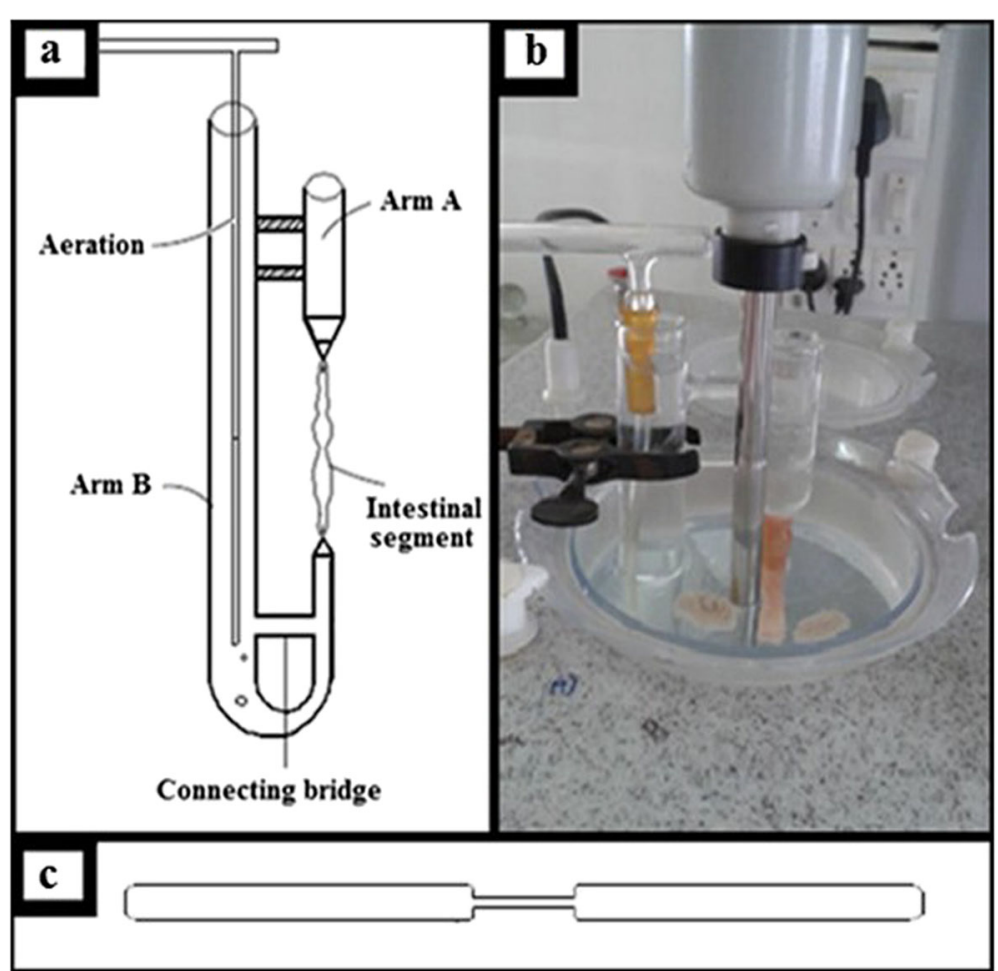

Fig. 1 Everted gut sac apparatus a U-shaped apparatus, b Assembly, c Glass rod

phosphate buffer pH $6.8(800 \mathrm{ml})$ as dissolution medium. To this, an ex vivo U-tube apparatus containing same buffer solution was assembled (Fig. 1b). Temperature was maintained at $37 \pm 0.5^{\circ} \mathrm{C}$ throughout study.

GTE and formulations (F1 to F9) (100 ml) were studied using the above mentioned assembly (Fig. 1b). Formulation was added in the dissolution medium and allowed to diffuse through an everted intestine into an ex-vivo apparatus. Five $\mathrm{ml}$ of aliquot was withdrawn from arm B (Fig. 1a) after every $15 \mathrm{~min}$ time interval for $150 \mathrm{~min}$, replacing equal volume of the solution and maintaining the temperature [27]. Drug was diffused from dissolution medium (mucosal side) to the serosal side (absorption compartment). The amount of diffused drug was analyzed UV spectrophotometrically. The experiment was repeated thrice using fresh dissolution medium as well as fresh intestinal segment each time.

\section{Selection of best formulation}

Curcumin was selected as permeation enhancer. The criterion for selection of the best batch was the formulation showing highest permeation of green tea extract through intestine. The best batch was subjected to UV-spectroscopy and RP-HPLC for analysis.

\section{HPLC analysis of formulation}

The best batch obtained at ex-vivo study was subjected to reverse phase HPLC using HPLC system
(Jasco, PU-2080Plus pump, UV-2075Plus detector) with C-18 column $(250 \mathrm{~mm} \times 40 \mathrm{~mm})$ having $5 \mu$ particle size at $274 \mathrm{~nm}$. Mobile phase used was acetonitrile: $0.1 \%$ ortho phosphoric acid (10:90). Flow rate was $1.2 \mathrm{ml} / \mathrm{min}$. Calibration curve was performed with standard concentrations of $10 \mathrm{ppm}$ to $70 \mathrm{ppm}$ with run time of $20 \mathrm{~min}$ [28].

\section{Diffusion study of formulation through tea bags}

Amount of green tea extract diffused through tea bags was determined by dunking tea bag $(220 \mathrm{mg})$ into a beaker with preheated $\left(80^{\circ} \mathrm{C}\right)$ distilled water $(100 \mathrm{ml})$ on magnetic stirrer (J. B. Scientifics, India) to simulate dip-dip movement of tea bag formulation. At predetermined time interval of $1 \mathrm{~min}$, one $\mathrm{ml}$ of aliquot was withdrawn, replacing same volume with distilled water and maintaining same temperature. After suitable dilution, samples were analysed by spectrophotometric method.

\section{In-vivo study}

Healthy Sprague Dawley rats (10 male and 10 female, weighing between 200 and $250 \mathrm{~g}$ and of age 6-7 weeks) were used to study hyperlipidemic activity. Animals were housed at temperature $21 \pm 1{ }^{\circ} \mathrm{C}$ and humidity $45-55 \%$ in polycarbonate cages by exposing alternate $12 \mathrm{~h}$ light and dark cycle.

The rats were divided into 5 groups (Group I to V), containing 4 rats in each group, two male and two 
female: Group I: Control; Group II: Negative control; Group III: Standard (Marketed group A); Group IV: Test group with high fat diet ad libitum and GTE solution (Test group B); Group V: Test group with high fat diet ad libitum and GTE plus curcumin solution (F2) (Test group C).

Initially the rats were acclimatized to laboratory conditions and were fed with commercially available standard diet and water. After initiation of the study, control group (Group I) was fed with normal diet and water ad libitum. Negative control group (Group II) was fed with high fat diet ad libitum(casein 12\%, corn starch $42.96 \%$, soybean oil $25 \%$, cholesterol $1 \%$, coline $0.04 \%$, salt mixture $5 \%$, vitamin mixture $1 \%$ and cellulose $13 \%)$. Test group A (Group III) was given high fat diet ad libitum for 15 days and liquid solution of marketed preparation atorvastatin (10 mg once a day) for further 15 days. Test group B (Group IV) was given high fat diet ad libitum for 15 days and GTE in solution form $(0.5 \mathrm{ml})$, once a day for further 15 days with a dose of $100 \mathrm{mg} / \mathrm{kg} /$ day. Test group C (Group V) was given high fat diet ad libitum for 15 days and F2 formulation in solution form $(0.5 \mathrm{ml})$, once a day, for further 15 days with a dose of $100 \mathrm{mg} / \mathrm{kg} /$ day. At the end of study period, all the animals were anesthetized using isoflurane anaesthesia, blood samples of all groups were collected from retroorbital sinuses and analysed for serum triglycerides, cholesterol, low density lipoproteins (LDL), High Density Lipoproteins (HDL), and Very Low density lipoproteins (VLDL) [29-31]. After collection of samples, the animals were humanly euthanized/ sacrificed using carbondioxide asphyxiation. The animal study was carried out as per the protocol approved by the Institutional Animal Ethics Committee of PRADO (Preclinical Research and Development Organisation) India, constituted as per the guidelines laid down by Committee for Purpose of Control and Supervision of Experiments on Animals (CPCSEA). The protocol approval no. is IAEC- 16-001.

\section{Statistical analysis}

Statistical analysis was performed by applying Graphpad Prism version 5 software (GraphPad Software Inc., La Jolla, CA). The experimental results were expressed as the mean \pm standard error of mean. The results were analyzed using one-way analysis of variance (ANOVA) with Bonferroni post-tests, where $p<0.001$ was considered as statistically significant.

\section{Stability study}

Herbal products are prone to microbial growth. Hence, stability of these formulations should be studied. Stability study of best batch was carried out to get a stable product which assured safety and efficacy, till shelf life, at defined storage and package conditions. Stability studies were carried out as per ICH guidelines to assess the combined effect of drug and excipients on stability of formulation. Best formulation was packed in tea bags, further in cardboard carton and kept in stability chamber (Thermolab, India) at $40{ }^{\circ} \mathrm{C} \pm 2{ }^{\circ} \mathrm{C} / 75 \% \mathrm{RH} \pm$ $5 \% \mathrm{RH}$. Samples were evaluated for any change in colour of powder, odour, microbial growth and drug content at 15 days interval for three months. Ex-vivo study was performed at the end of three months.

\section{Results}

\section{Characterisation of green tea extract}

Yield of green tea extract was found to be $7.45 \%$. The dried and triturated form of powder extract was brownish in colour, having pungent odour and yield of $10 \%$.

\section{Flow properties}

Angle of repose of GTE powder was found to be $43^{\circ}$, which demonstrated passable flow character. Compressibility index and Hausner's ratio was $20 \%$ and 1.25 respectively, which indicates good flow characteristic.Preliminary phytochemical screening done for EGCG by performing catecholic tannin test showed green black colour and confirmed the presence of catecholic tannin.

\section{Analysis of EGCG in green tea extract by HPTLC}

HPTLC of green tea extract was carried out to confirm the presence of active molecule mainly epigallocatechin gallate in the green tea extract. HPTLC was performed keeping experimental conditions constant. Sample plate on which green tea extract was applied showed strong peak at $R_{f}$ value 0.12.Standard $R_{f}$ value for pure EGCG was found to be 0.12 . The obtained results were in agreement with earlier work $[24,25]$.

\section{Infra-red spectroscopy}

IR spectrum of green tea extract (Fig. 2a) showed sharp peak at $3745 \mathrm{~cm}^{-1}$ demonstrating presence of $-\mathrm{OH}$ group. Strong peak at $1694 \mathrm{~cm}^{-1}$ showed presence of $\mathrm{C}=\mathrm{O}$ group of aryl ketone. Multiple bands at $1515 \mathrm{~cm}^{-1}, 1530 \mathrm{~cm}^{-1}$, $1549 \mathrm{~cm}^{-1}, 1563 \mathrm{~cm}^{-1}$ stretch indicated presence of aromatic $\mathrm{C}=\mathrm{C}$ group. One band at $1738 \mathrm{~cm}^{-1}$ showed presence of $\mathrm{C}=\mathrm{O}$ stretch group of ester and two bands at $1041 \mathrm{~cm}^{-1}$ and $1005 \mathrm{~cm}^{-1}$ indicated exist of C-O stretch of ester group.

IR spectrum of pure curcumin (Fig. 2b) indicated broad strong peak at $3837 \mathrm{~cm}^{-1}$ indicating presence of hydrogen bonded alcoholic $-\mathrm{OH}$ group. Strong sharp free peak at $3743 \mathrm{~cm}^{-1}$ indicated presence of alcoholic -OH group. Peak at $1742 \mathrm{~cm}^{-1}$ indicated presence of aldehyde $\mathrm{C}=\mathrm{O}$ group. Multiple bands at $1509 \mathrm{~cm}^{-1}$ and $1541 \mathrm{~cm}^{-1}$ showed presence of aromatic $\mathrm{C}=\mathrm{C}$ group. Peak at $1151 \mathrm{~cm}^{-1}$ and $670 \mathrm{~cm}^{-1}$ in dicated alcoholic $\mathrm{C}-\mathrm{O}$ stretch group and alkene $=\mathrm{C}-\mathrm{H}$ 


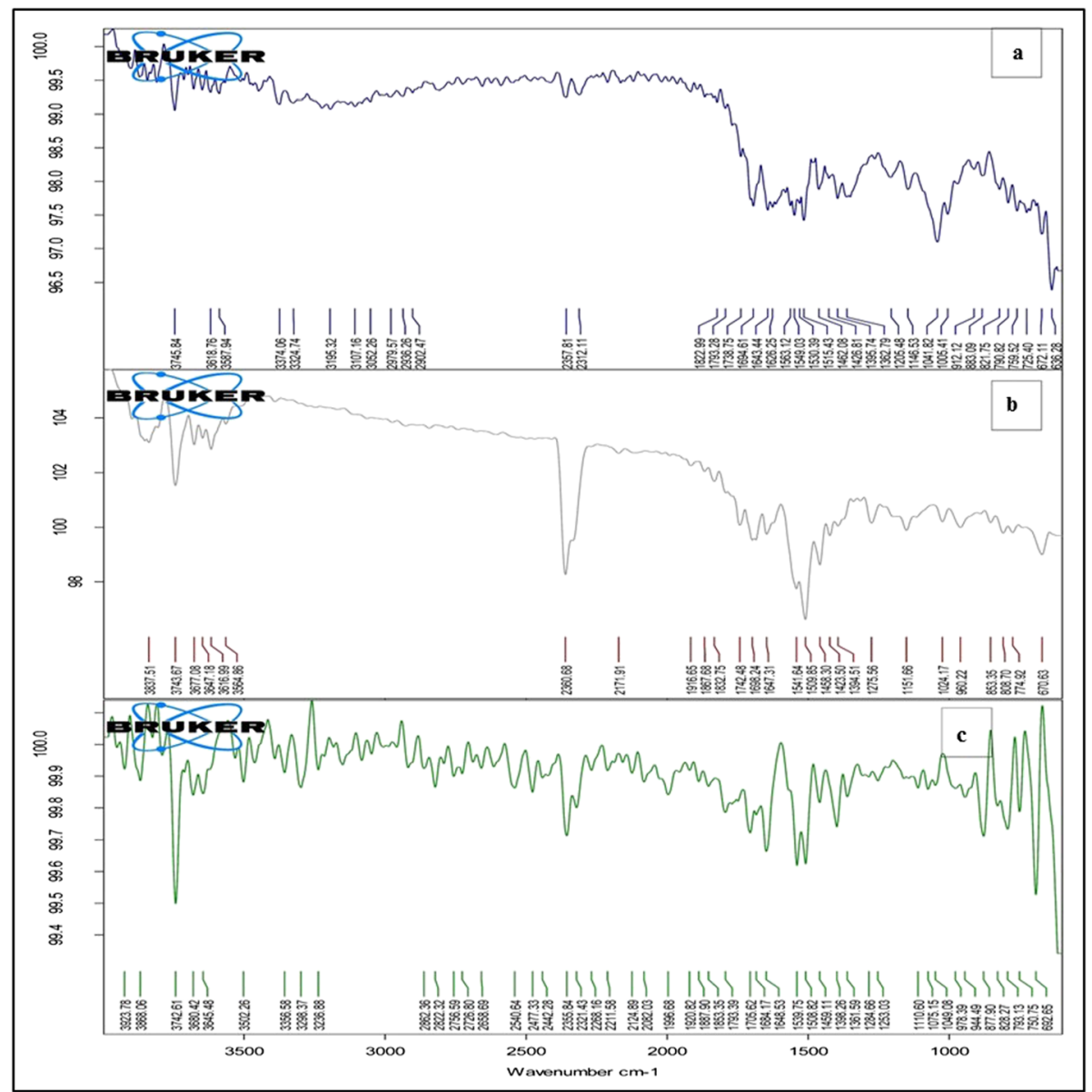

Fig. 2 Infrared spectra of a Green tea extract, b Curcumin, and c Mixture

group respectively.IR spectrum (Fig. 2c) of mixture of extract and curcumin showed presence of all bands of both components indicating no chemical interaction of both the components.

\section{Differential scanning calorimetry}

Figure 3a shows thermogram of green tea extract. A broad peak was observed at $73^{\circ} \mathrm{C}$, and a small plateau at $223^{\circ} \mathrm{C}$. Figure $3 \mathrm{~b}$ shows thermogram of pure curcumin, which indicated a sharp peak near $179^{\circ} \mathrm{C}$. Figure 3c shows thermogram of mixture of green tea extract and curcumin which demonstrated peaks due to physical interaction, indicating no chemical interaction between two components [32].

\section{Tensile strength of tea bag}

Good strength and integrity of tea bag was obtained at peak load of $4210 \mathrm{~g}$ at trigger load of $5 \mathrm{~g}$. The result indicates strength and integrity of tea bags to protect content from damages during transport and formulation in hot water.

\section{Evaluation of tea bag formulation Drug content}

Drug content was found as follows: F1 (97.2\%), F2 (96.21\%), F3 (97.4\%), F4 (96.5\%), F5 (95.25\%), F6 (95.45\%), F7 (94.25\%), F8 (93.98\%) and F9 (92.8\%).

\section{Ex-vivo studies by UV spectrophotometer}

Drug permeation of GTE was found to be $21.64 \%$. From Fig. 4, it was inferred that at equal concentrations of curcumin in F4 (34.52\%) and F7 (24.28\%), curcumin might have permeated through intestine, as green tea extract particularly EGCG, inhibited the P-glycoprotein pump. In case of $F 1$ (13.27\%), due to insufficient quantity of curcumin, P-gp pump might not be inhibited resulting in less permeation of GTE. At highest concentrations of curcumin in F6 (36.8\%) and F9 (27.73\%), curcumin itself might got absorbed into the systemic circulation due to inhibition of P-gp pump by EGCG. F5 (41.39\%) and F8 (40.09\%) showed intermediate permeation compared to other formulations. F2 showed highest permeation (57.64\%) of ECGC amongst all 


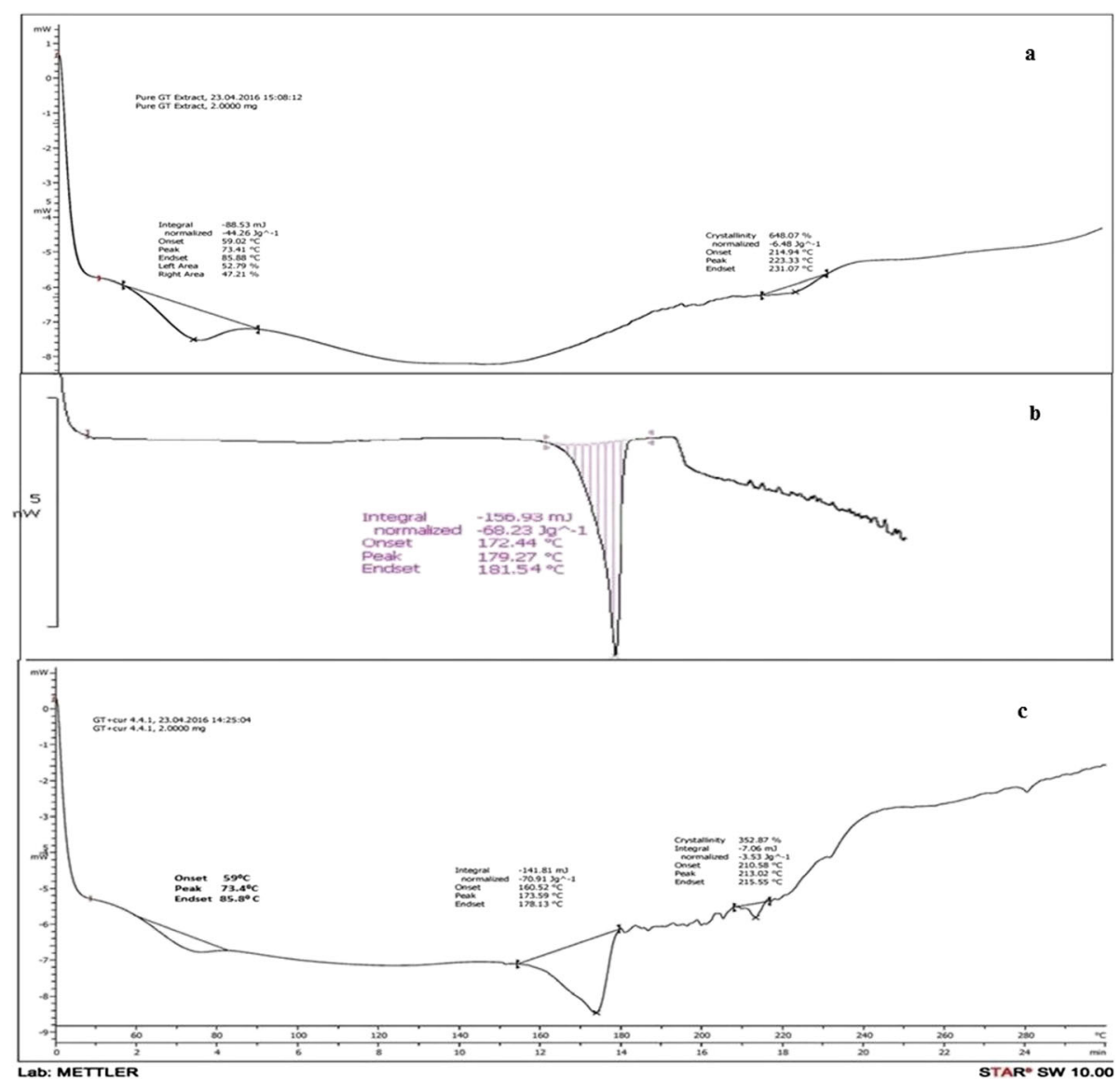

Fig. 3 DSC thermogram of $\mathbf{a}$ Green tea extract, $\mathbf{b}$ Curcumin, $\mathbf{c}$ Mixture

formulations owing to inhibition of P-gp pump by curcumin. P-glycoprotein pump inside intestine can be potential mechanism based on literature to enhance permeability of EGCG. Therefore, $50 \mathrm{mg}$ and $220 \mathrm{mg}$ of curcumin and GTE respectively were sufficient to inhibit P-gp pump of EGCG, enhancing the permeability of GTE.

\section{Ex-vivo studies by RP-HPLC}

Samples of ex-vivo studies of F2 and pure GTE were analysed and confirmed by HPLC. HPLC results were in close agreement with earlier results obtained by UVvisible spectrophotometer. The drug permeated across the intestine from pure GTE and formulation (F2) was

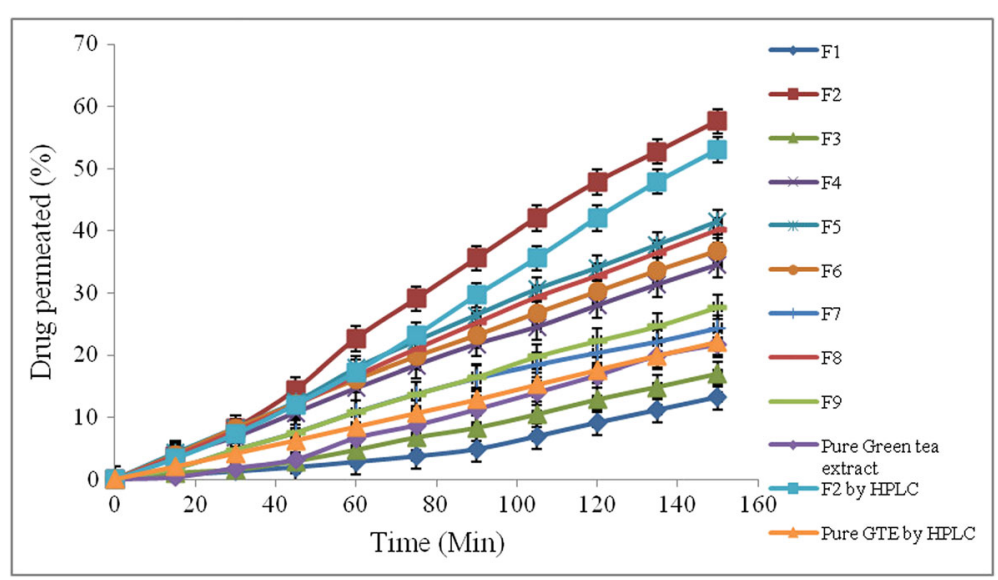

Fig. 4 Ex-vivo study of drug permeated through intestine 
found to be 20.67 and $55.02 \%$ respectively by HPLC method.This study confirmed pivotal role of curcumin as permeation enhancer to enhance bioavailability of GTE from the intestine, by inhibition of P-gp pump and by enzyme inhibition.

\section{Diffusion study}

Diffusion study of tea bag formulations showed greatest amount of GTE and curcumin diffused across the tea bag membrane (96 and 97\% respectively in $7 \mathrm{~min}$ ).

\section{In-vivo studies}

Results of blood samples analysed for cholesterol, triglycerides, LDL, HDL and VLDL are shown in Fig. 5.Serum lipid content in Group II (negative control) confirmed significant induction of hyperlipidemia. Serum cholesterol level of Group II was $100.75 \pm 2.5 \mathrm{mg} / \mathrm{dl}$ with $p<0.001$. This was easily comparable with serum cholesterol level of Group I (control group) $(63.25 \pm 4.19 \mathrm{mg} / \mathrm{dl}, \mathrm{p}<0.001)$ .Group III (Test A) showed regulation of lipid with lowered cholesterol $(84.74 \pm 4.34 \mathrm{mg} / \mathrm{dl}, \quad \mathrm{p}<0.001)$, lipoproteins $(\mathrm{LDL}=44.15 \pm 2.53 \mathrm{mg} / \mathrm{dl}, \mathrm{VLDL}=11.9 \pm 0.62 \mathrm{mg} / \mathrm{dl}$ with $\mathrm{p}<0.001)$ and triglycerides $(59.5 \pm 3.1 \mathrm{mg} / \mathrm{dl}, \quad \mathrm{p}<0.001)$ and increased values of HDL $(52.5 \pm 2.64 \mathrm{mg} / \mathrm{dl})$. Group IV (Test B) showed significant lipid regulating effects as compared to negative control group (cholesterol $=90 \pm 1.82$ $\mathrm{mg} / \mathrm{dl}, \quad$ triglycerides $=85.5 \pm 2.08 \mathrm{mg} / \mathrm{dl}, \quad \mathrm{HDL}=46 \pm 2.16$ $\mathrm{mg} / \mathrm{dl}, \quad \mathrm{LDL}=46 \pm 2.16 \mathrm{mg} / \mathrm{dl}, \quad \mathrm{VLDL}=17.1 \pm 0.41 \mathrm{mg} / \mathrm{dl})$ with $\mathrm{p}<0.001$. Group V (Test C) (F2) showed more significant lipid regulating effects than Group IV (Test B), depicting effectiveness equal to standard marketed preparation in Test $\mathrm{A}$ group (cholesterol $=80 \pm 1.82 \mathrm{mg} / \mathrm{dl}$, triglycerides $=$ $73.25 \pm 2.21 \mathrm{mg} / \mathrm{dl}, \mathrm{HDL}=50.75 \pm 1.7 \mathrm{mg} / \mathrm{dl}, \mathrm{LDL}=43.9 \pm$ $1.93 \mathrm{mg} / \mathrm{dl}, \mathrm{VLDL}=14.65 \pm 0.44 \mathrm{mg} / \mathrm{dl}$ with $\mathrm{p}<0.001$ ) [33].

\section{Stability study}

Formulation showed no microbial growth and retention of its brownish colour. Drug content of formulation after 15 days and three months was 96.11 and $96.01 \%$ respectively. Ex-vivo study showed drug permeation of 57.23 and $57.12 \%$ respectively, after 15 days and three months. Thus, tea bag formulation was found to be stable.

\section{Discussion}

\section{Phytochemical investigation}

Preliminary phytochemical screening and HPTLC study confirmed exist of catecholic tannin and EGCG in green tea extract.IR spectrum and DSC thermogram of individual and mixture of extract and curcumin showed presence of all bands and peaks of both components indicating no chemical interaction of both the components. Drug content of F1 to F9 batches was found in the range of 91 to $97 \%$, thus confirming uniformity of content from batch to batch.

\section{Ex-vivo studies}

Ex-vivo studies confirmed highest amount of EGCG permeated across the gut, through formulation F2, analyzed by both UV and HPLC method. Therefore, F2 was selected as the best batch. Diffusion study of tea bag formulations showed maximum amount of GTE and curcumin diffused across the tea bag membrane. Thus, formulation F2 containing mixture of GTE and curcumin depicted higher lipid regulating effect than pure GTE. Reason for this could be enhanced bioavailability of GTE in presence of curcumin.

\section{In vivo studies}

In vivo study showed no toxic effects of GTE or curcumin in rats at $100 \mathrm{mg} / \mathrm{kg} /$ day dose of formulation. Rats were

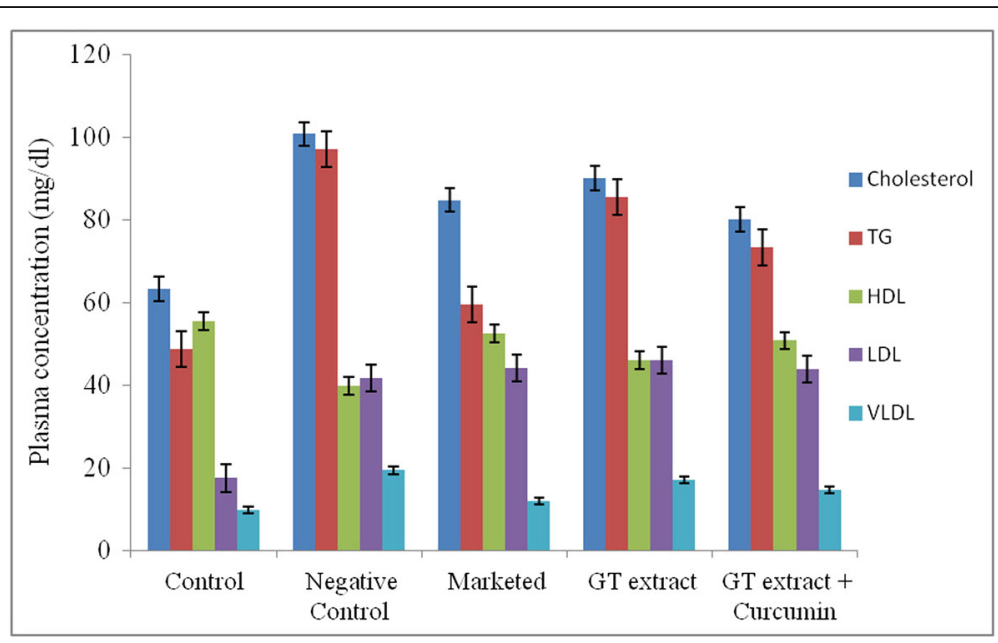

Fig. 5 Lipid profile of in-vivo study in rats. Data is expressed as Mean \pm SD of $n=4$, statistical significance $P<0.01$ 
healthy throughout the study. In-vivo study, thus, supported ex-vivo study of increased permeability and then bioavailability of GTE by adding curcumin, leading to more significant serum lipid regulating effect in rats. The results obtained are in close agreement with earlier observations of green tea extract and lactobacillus strain [29]. One of the underlying mechanism by which EGCG affects lipid metabolism is by interfering with the luminal emulsification, hydrolysis, and micellar solubilization of lipids and cholesterol in the digestive tract, which in turn decrease uptake of lipids and cholesterol absorption [34]. This may be due to complex formation of EGCG with lipids and lipolytic enzymes. Green tea or catechins may also influence the uptake and intracellular processing of lipids and assembly and secretion of chylomicrons [35]. EGCG with curcumin thus can be a potential candidate to reduce hyperlipidemia. Promising results can be expected with increase in time period of the study. Stability study showed stable formulation of tea bags.

\section{Conclusion}

Formulation of herbal tea bags was developed containing green tea extract using curcumin as a permeation enhancer. Curcumin enhanced permeation of green tea extract, mainly epigallocatechin gallate (EGCG), which is the most important active constituent of green tea extract. Formulation fulfilled dose requirement and regulated serum lipid levels significantly compared to pure green tea extract (without curcumin), with no side effects. Curcumin, thus can be an effective permeation enhancer to increase bioavailability of EGCG present in green tea, effectively reducing the hyperlipidemia. Ease and convenience of tea bags make it suitable for even bed-ridden patients. The novel concept of tea bags achieves the patient compliance.

\section{Acknowledgements}

Authors thank Preclinical Research and Development Organisation (PRADO), India, for in vivo study guidance.

\section{Authors' contributions}

AP and VP designed and directed the research work, SJ performed and carried out the research work, and PD helped in development of analytical method and took the lead in writing the manuscript. All authors provided critical feedback and helped to shape the research, analysis and manuscript. All authors read and approved the final manuscript.

\section{Funding}

The authors declare that there is no funding for the research work.

\section{Availability of data and materials}

All data generated or analyzed during this study are included in this published article.

\section{Ethics approval}

The animal study was carried out as per the protocol approved by the Institutional Animal Ethics Committee of PRADO (Preclinical Research and Development Organisation) India, constituted as per the guidelines laid down by Committee for Purpose of Control and Supervision of Experiments on Animals (CPCSEA). The protocol approval no. is IAEC- 16-001.
Consent for publication

Not applicable.

\section{Competing interests}

The research work has no financial assistance. The authors declare that they have no competing interests.

\section{Author details}

'Department of Pharmaceutics, JSPM's Rajarshi Shahu College of Pharmacy and Research, Tathawade, Pune, Maharashtra 411033, India. ${ }^{2}$ Department of Pharmaceutical Chemistry, JSPM Rajarshi Shahu College of Pharmacy and Research, Tathawade, Pune, Maharashtra 411033, India.

Received: 18 January 2018 Accepted: 3 June 2019

Published online: 13 June 2019

\section{References}

1. Tuhin RH, Begum MM, Rahman MS, Karim R, Begum T, Ahmed SU, Mostofa R, Hossain A, Abdel-Daim MM, Begum R. Wound healing effect of Euphorbia hirta Linn. (Euphorbiaceae) in alloxan induced diabetic rats. BMC Complement Altern Med. 2017:17:423.

2. Pandey KB, Rizvi SI. Plant polyphenols as dietary antioxidants in human health and disease. Oxidative Med Cell Longev. 2009;2(5):270-8.

3. Wolfram S, Raederstorff D, Preller M, Wang Y, Teixeira SR, Riegger C, Weber P. Epigallocatechingallate supplementation alleviates diabetes in rodents. J Nutr. 2006;136:2512-8.

4. Ahmad RS, Butt MS, Sultan MT, Mushtaq Z, Ahmad S, Dewanjee S, Feo VD, Zia-Ul-Haq M. Preventive role of green tea catechins from obesity and related disorders especially hypercholesterolemia and hyperglycemia. J Transl Med. 2015;4:13-79. https://doi.org/10.1186/s12967-015-0436-x.

5. Ramadan G, Nadia M, El-BeihAbd El-Ghffar EA. Modulatory effects of black vs. green tea aqueous extract on hyperglycaemia, hyperlipidaemia and liver dysfunction in diabetic and obese rat models. Brit J Nutr. 2009;102:1611-9.

6. Mohan H. Textbook of pathology. Fourth ed. New Delhi: Jaypee Publications; 2000. p. 802-11.

7. Roghani M, Baluchnejadmojarad T. Hypoglycemic and hypolipidemic effect and antioxidant activity of chronic epigallocatechin-gallate in streptozotocin-diabetic rats. Pathophysiology. 2010;17:55-9.

8. Al-Sayed E, Abdel-Daim MM. Analgesic and anti-inflammatory activities of epicatechin gallate from Bauhinia hookeri. Drug Dev. Res. 2018;79:157-64.

9. Al-Sayed E, Abdel-Daim MM, Kilany OE, Karonen M, Sinkkonen J. Ren Fail. 2015;37(7):1198-207.

10. Steinmann J, Buer J, Pietschmann T, Steinmann E. Anti-infective properties of epigallocatechin-3-gallate (EGCG), a component of green tea. $\mathrm{Br} J$ Pharmacol. 2013;168:1059-73.

11. Derliz $M$, Hunstein W. Epigallocatechin-3-gallate (EGCG) for clinical trials: more pitfalls than promises? Int J Mol Sci. 2011:12:5592-603.

12. Zaveri NT. Green tea and its polyphenolic catechins: medicinal uses in cancer and noncancer applications. Life Sci. 2006;78:2073-83.

13. Koo SI, Noh SK. Green tea as inhibitor of the intestinal absorption of lipids: potential mechanism for its lipid-lowering effect. J NutrBiochem. 2007:18:179-83.

14. Singh DK, Banerjee S, Porter TD. Green and black tea extracts inhibit HMGCoA reductase and activate AMP-kinase to decrease cholesterol synthesis in hepatoma cell. J Nutr Biochem. 2009;20:816-22.

15. Klinski E, Semov A, Yan X, Alakhov V, Muyzhnek E, Kiselev V. Block copolymer based composition of epigallocatechin-3-gallate with improved oral bioavailability as a way to increase its therapeutic activity. J NanomedicineBiotherapeuticDiscov. 2013;3:1-5.

16. Kanwar J, Taskeen M, Mohammad I, Huo C, Chan TH, Dou QP. Recent advances on tea polyphenols. Front Biosci. 2012;4:111-31.

17. Abdel-Daim MM, Abdou RH. Protective effects of diallyl sulfide and curcumin separately against thallium-induced toxicity in rats. Cell J. 2015;17(2):379-88.

18. Ajazuddin AA, Qureshi A, Kumari L, Vaishnav P, Sharma M, Saraf S, Saraf S. Role of herbal bioactives as a potential bioavailability enhancer for active pharmaceutical ingredients. Fitoterapia. 2014:97:1-14.

19. Li M, Cui J, Ngadi MO, Ying M. Absorption mechanism of wheyprotein-delivered curcumin using Caco-2 cell monolayers. Food Chem. 2015;180:48-54. 
20. Lambert DJ, Hong J, Kim HD, Mishin MV, Yang SC. Piperine enhances the bioavailability of the tea polyphenol-epigallocatechin-3-gallate in mice. J Nutr. 2004;134:1948-52.

21. Dube A, Joseph A, Nicolazzo LI. Chitosan nanoparticles enhance the intestinal absorption of the green tea catechins $(+)$ - catechin and $(-)$ epigallocatechingallate. Eur J Pharm Sci. 2010;4:219-25.

22. Onoue S, Ochi M, Yamada S. Development of (-)-epigallocatechin-3-gallate (EGCG)-loaded enteric microparticles with intestinal mucoadhesive property. Int J Pharm. 2011:410:111-3.

23. Bazinet L, Labb'e D, Tremblay A. Production of green tea EGC- and EGCGenriched fractions by a two-step extraction procedure. Sep Purif Technol. 2007;56:53-6.

24. Elias M, Antony B. Quantitative determination of epigallocatechingallate present in green tea extract by HPTLC. Ind J Pharm Sci. 2001;63:419-20.

25. Reich E, Schibli A, Widmer V, Jorns R, Wolfram E, DeBatt A. HPTLC methods for identification of green tea and green tea extract. J Liq Chrom Related Tech. 2006;29:2141-51.

26. Pandit AP, Tekade AR, Devkar TB, Divase GT, Rodde MS. An apparatus for conducting ex vivo studies on tissues. 2012. Indian Patent; 2363/MUM/2012.

27. Dixit $\mathrm{P}$, Jain DK, Dumbwani J. Standardization of an ex vivo method for determination of intestinal permeability of drugs using everted rat intestine apparatus. J Pharmacol Toxicol Methods. 2012;65:13-7.

28. Fangueiro JF, Parra A, Silva AM, Egea MA, Souto EB, Garcia ML, Calpena AC. Validation of a high performance liquid chromatography method for the stabilization of epigallocatechingallate. Int J Pharm. 2014;475:181-90.

29. Karaca T, Bayıroglu F, Cemek M, Comba B, Ayaz A, Karaboga I. Effects of green tea extract and lactobacillus casein strain shirota on levels of serum minerals, cholesterol, triglycerides, glucose and lactate in rats fed on highcarbohydrate and high-lipid diets. J Med Sci. 2013;3:1-7.

30. Thirumalai T, Tamilselvan N, David E. Hypolipidemic activity of Piper betel in high fat diet induced hyperlipidaemic rat. J Acute Dis. 2014;3:131-5.

31. Lee SM, Kim CW, Kim JK, Shin HJ, Baik JH. GCG-rich tea catechins are effective in lowering cholesterol and triglyceride concentrations in hyperlipidemic rats. Lipids. 2008;43:419-29.

32. Peng Y, Wu Y, Li Y. Development of tea extracts and chitosan composite films for active packaging materials. Int J Bio Macromol. 2013;59:282-9.

33. Ihedioha J, Noel-Uneke $\mathrm{O}$, Ihedioha T. Reference values for the serum lipid profile of albino rats (Rattusnorvegicus) of varied ages and sexes. Comp Clin Pathol. 2013;22(1):93-9. https://doi.org/10.1007/s00580-011-1372-7.

34. Raederstorff DG, Schlachter MF, Elste V, Weber P. Effect of EGCG on lipid absorption and plasma lipid levels in rats. J Nutr Biochem. 2003;14:326-32.

35. Koo SI, Noh SK. Green tea as inhibitor of the intestinal absorption of lipids: potential mechanism for its lipid-lowering effect. J Nutr Biochem. 2007:18:179-83.

\section{Publisher's Note}

Springer Nature remains neutral with regard to jurisdictional claims in published maps and institutional affiliations.

Ready to submit your research? Choose BMC and benefit from:

- fast, convenient online submission

- thorough peer review by experienced researchers in your field

- rapid publication on acceptance

- support for research data, including large and complex data types

- gold Open Access which fosters wider collaboration and increased citations

- maximum visibility for your research: over $100 \mathrm{M}$ website views per year

At BMC, research is always in progress.

Learn more biomedcentral.com/submissions 